\title{
Stabilising Potential of Sawdust Lignin-based Extracts in Compressed Lateritic Bricks
}

\author{
Fadele, O.A. ${ }^{*}$ and Ata, O.1
}

\begin{abstract}
Lignocellulosic materials are abundant in nature, rich in some functional groups, considered less harmful to human health and the environment.The resulting waste may be recycled for other beneficial uses. Lignin is known to be a natural binder in lignocellulosic materials and several studies have confirmed it has binding ability with soil particles. This paper studied its stabilising potential in compressed lateritic bricks, especially its effects on density and compressive strength properties of the bricks. Lignin additives extracted from sawdust were used to stabilise laterite, while the bricks were moulded with the UNIFE ram, a type of the CINVA ram. The laterite was stabilised at $4 \%, 8 \%$, and $12 \%$, while cement stabilised samples and $0 \%$ (unstabilised laterite) samples prepared accordingly were used as controls. The results showed that the LBAs contributed to the strength gained by the bricks at 3, 7, 14, and 28 days air curing, while the bricks samples were categorised as high density.
\end{abstract}

Keywords: Compressed lateritic bricks; compressive strength; density; lignin based additives; stabilization.

\section{Introduction}

The use of laterite blocks in construction of buildings has been an ancient practice which is gradually regaining interest in modern day construction. This is partly due to its many benefits over some conventional masonry units and concrete, the increasing housing need in some developing countries amidst dwindling economy, and the quest for environmental sustainability with respect to materials utilisation for construction works. Lateritic blocks are environmental-friendly and can regulate the indoor climate. The materials for its production can be sourced readily within the immediate environment and processed with minimal efforts and simple tools. However, in developing nations like Nigeria, the major drawback to its commercialisation and wider adoption as walling units arises from its lack of stability and durability when exposed to high moisture [1], which necessitates the need to stabilise it with high amount of cement or lime depending on the type of earth material used. Yet, the production of calcareous binders have been associated with the continuous depletion of nature's non-renewable resources, consumption of substantial energy and contribution to carbon dioxide emission into the atmosphere.

${ }^{1}$ Department of Building ObafemiAwolowo University, Ile-Ife, NIGERIA.

* Corresponding author:damilola4fa4@gmail.com

Note: Discussion is expected before June, $1^{\text {st }} 2018$, and will be published in the "Civil Engineering Dimension", volume 20, number 2, September 2018.

Received 01 October 2017; revised 26 February 2018; accepted 01 March 2018.
The noticeable effects of this, evident in the increasing day time heat and rapid seasonal fluctuation witnessed globally necessitates the use of alternative binders considered to be environmentalfriendly in order to reduce the impact on the environment.

Lignin additives or admixtures are gradually gaining research interest as it is considered to be environment friendly and renewable in nature if properly managed. Presently, the major sources of lignin additives are the paper industry and biofuel plants, where lignin in various forms and types are obtained as waste stream from the conversion of different lignocellulosic materials. Lignin from the paper industry is said to contain sulphur, while that from biofuel plants is sulphur free.The two forms of lignin have been investigated as stabilising additive in road applications, either solely or in combination with other conventional binders. Previous studies [2-4] have attributed binding ability to lignin when used with soil materials. Also, Nicholls and Davidson[5] established that lignin additives increase the strength and stability of stabilised soil samples, which improve with increasing air curing period. Furthermore, an investigation was done by Palmer et al. [6] on the behaviour of lignin and two divalent chloride salts of calcium and magnesium in three different soil samples. The study found out that lignin stabilised sandy gravel soil showed significant improvement in strength gained at all the stabilisation levels studied. Also, Ceylan et al.[7] studied the utilisation of sulphur free lignin in soil stabilisation using two different co-products, one in liquid form and the other in powdery form. 
The result of the tests indicated that both additives were effective in stabilising the Iowa class 10 soil, classified as CL or A-6(8), with improvement in strength and moisture resistance.

Another study investigated the stabilising effects of electrolyte lignin on some engineering properties of black cotton soil, which contains significant amount of clay fraction, for road construction. It was noted that the consistency limits, moisture density properties, compressive and bearing strength of treated soil samples were improved significantly, while the fatigue test showed a durable stabilised sample with considerable reduction in swelling of the electrolyte lignin stabilised samples [8].

Also, the study of Canakciet al. [9] further revealed that lignin reduced the liquid limits and plasticity index of the stabilised soil samples when compared with rice husk ash stabilised samples. Also, the lignin stabilised samples showed higher strength gained which improved with increasing additive content and curing age and a lower swelling when compared with that of the rice husk additives investigated.

The study by Maskell et al.[10] investigated the use of lignosulphonates in extruded earth blocks. The study noted that the inclusion of lignosulphonate based stabiliser had a significant effect on the dry compressive strength of blocks, but not the wet compressive strength of concrete. The study further noted that the strength improvement could be attributed to the cation exchange process and likewise to the adhesive nature of the lignosulphonate.

All the studies mentioned above have demonstrated the possible utilisation of different forms of lignin with different soil materials for construction purposes and showed it as a potential soil stabilising agent with improved strength property. However, lignin from either paper or biofuel waste stream may not be directly obtained in a developing country like Nigeria due to low industrial activities. Hence, the potentials of lignin compounds obtained from lignocellulosic waste materials like sawdust which abound in the country was explored for possible utilisation as stabilising additives for lateritic blocks in this study. This is with a view to reduce the dependence on calcareous binders, increase the adoption of stabilised block walling subject to improve performance, enhance environmental sustainability as a result of recycling supposed waste materials and hence ensure a cleaner environment.

\section{Materials and Methods}

The lateritic soil used for this study was obtained from a borrow pit located within the Obafemi Awolowo University, Ile-Ife, Nigeria, from which samples have previously been obtained for road construction purpose. The laterite sample was separated into two fraction after the removal of coarser gravel fraction (particles greater than $10 \mathrm{~mm}$ ) and unwanted debris. One of the samples was sieved to obtain particles size finer than $2.36 \mathrm{~mm}$ (referred to as the sieved sample), while the other sample was used raw (referred to as unsieved). Consistency limits test, compaction test and mineralogical classification test were carried out on the laterite samples. The results of the test are presented in Table 1.

Table 1. Summary of the Characteristics of Laterite Sample

\begin{tabular}{lc}
\hline \multicolumn{1}{c}{ Soil property } & $\begin{array}{c}\text { Percentage } \\
\text { composition/ } \\
\text { classification }\end{array}$ \\
\hline Particle gradation & \\
Gravel & 15 \\
Sand & 44 \\
Silt and clay & 41 \\
\hline Consistency & \\
Liquid limit, LL & 57.66 \\
Plastic limit, PL & 37.41 \\
Plasticity index, PI & 20.25 \\
Natural moisture content & 7.96 \\
\hline Classification of laterite & \\
USCS & MH (sandy elastic \\
& silt with gravel) \\
AASHTO & between A-5 and A-6 \\
& (silty-clayey soil) \\
\hline Compaction (Moisture-Density) & \\
Maximum dry density, kg/m ${ }^{3}$ (UNS) & 1970 \\
Optimum moisture content, \% & 27.5 \\
Maximum dry density, kg/m ${ }^{3}$ (SS) & 1930 \\
Optimum moisture content, \% & 26 \\
\hline Mineralogical test & \\
Kaolinite (Al 2 SiO5(OH) 4 ) & 53.26 \\
Quartz (SiO ${ }_{2}$ ) & 46.74 \\
\hline
\end{tabular}

Three additives were used, a conventional binder ordinary portland cement, (OPC type 1), lignin additives obtained from particular softwood (Ceiba Pentandra), and hardwood sawdust; based on availability. The sawdust samples were subjected to alkaline hydrolysis in a pressured vessel using sodium hydroxide solution as the white liquor, following the procedure that has been reported previously[11,12]. Alkaline hydrolysis was selected based on its benefits of minimal treatment conditions when compared with other methods available, while sodium hydroxide was also noted [13] to be the most frequently used in laboratory investigations. As it is possible to extract hydroxide locally from waste materials, this may subsequently be explored given satisfactory performance of the tested additives. The extracts from the additives were used as obtained to stabilise the laterite samples at $4 \%, 8 \%$, and $12 \%$ by mass of the laterite content. The unstabilised samples representing $0 \%$ and cement stabilised samples at $4 \%$, 
$8 \%$, and $12 \%$ by mass of laterite were used to measure the effectiveness of the wood additives.

The bricks samples were prepared from the mixed lateritic soil using the optimum moisture content obtained through the proctor test and were moulded with UNIFE Ram with an average dimension of 285 x 130 x $115 \mathrm{~mm}$. The wet laterite mixtures were placed in two layers with each layer compacted while the bricks were removed from the ram and cured in polythene sheets for the first 3 days. This was to minimise loss of moisture and shrinkage as well as to gain sufficient strength for handling. Then, the bricks were stacked on a platform in the laboratory to allow free circulation of air around the stacks till the testing age maturation. The effects of the additives on the density and compressive strength of bricks were measured at 3, 7, 14, and 28 days, respectively, while the cement-stabilised samples were subject to wetting by sprinkling at regular intervals.

\section{Discussion of Results}

\section{Classification of Input Materials}

According to USCS, the laterite sample is sandy elastic silt with gravel (MH), while according to ASSHTO, it is a clayey laterite (A-5/6), whereas the dominant clay mineral is kaolinite. Kaolinite is known to be stable in moisture due to the presence of alternating sheets of alumina and silica held by hydrogen bonding [14], while it undergoes little substitution and hence little cation exchange [15]. This may influence the response of the laterite sample to each of the treatment. The results of FTIR analysis on the lignin additives (presented in Figure 1 for hardwood and Figure 2 for softwood, respectively) showed some level of surface activities and the presence of phenolic hydroxyl $(-\mathrm{OH})$ structure which is the dominant group present at wavelength band (3317 to 3342 ) $\mathrm{cm}^{-1}$ and (3207 to 3244 ) $\mathrm{cm}^{-1}$ for hardwood and softwood, respectively. Also, the presence of $\mathrm{C}=\mathrm{C}$ typical of benzene ring at (1638$1665) \mathrm{cm}^{-1}$ and (1638 to 1667 ) $\mathrm{cm}^{-1}$ band and C-C, C$\mathrm{O}, \mathrm{C}-\mathrm{H}$ stretching linked to polysaccharides at (1016 to 1087$) \mathrm{cm}^{-1}$ and (1016 to 1088 ) $\mathrm{cm}^{-1}$ for the hardwood and softwood, respectively, were detected.

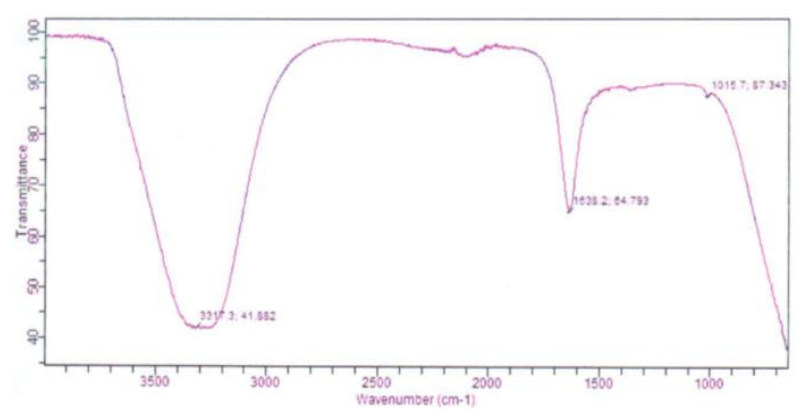

Figure 1. Infra-red Spectra of Hardwood Lignin Extract

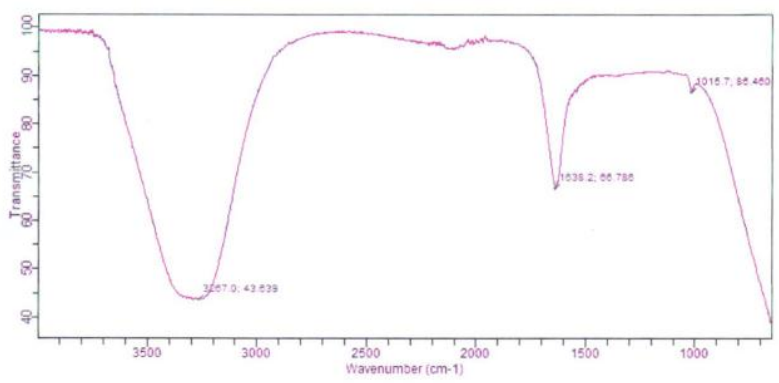

Figure 2. Infra-red Spectra for the Softwood Lignin Extract

\section{Density}

The densities of both the stabilised and control samples were presented in Table 2 and Table 3 for the unsieved (U) and sieved (S) samples for an average of three bricks per experiment. From the results obtained, it was noted that the effect of particle gradation had influence on the density of the bricks, while the unsieved samples have higher density values compared to the sieved ones. Also, the result further indicated that density varied with additive type, additive content and curing age. This is comparable to the results obtained by Gopalakrishnan et al. [16], as it showed a similar trend, while the density values are also within close range. The British code BS EN 771-1 recommends density as part of the properties by which bricks may be specified. Bricks with density exceeding 1000 $\mathrm{kg} / \mathrm{m}^{3}$ may be classified as high density bricks, designated as HD. Generally, given the range of the densities of the sample bricks across the various parameters studied, the bricks can be said to be of high density. This is actually expected and is comparable with the values obtained by Kim et al. [17], although the samples by the latter were prepared for road construction. The variations in the densities across the parameters studied may be associated with changes in the moisture content of the bricks as they undergo drying with increasing curing age. It may also be attributed to the likely particles rearrangement in the bulk of the bricks as the additives interact with the particles in the presence of moisture. Also the method of compaction of the bricks may also contribute to the trend noticed.

\section{Compressive Strength}

Compressive strength is another important property required by BS 772 for specifying bricks quality, and it is also an indication of the structural suitability of the brick. The results of the compressive strength test are shownin Figure 3 and Figure 4. The results showed that, generally, for all the additive types, there was an increase in the values of strength gained as the curing age and additive content increased, although the rate of gain of strength varied with additive types and curing age. 
Table 2. Density of the Unsieved Brick Samples

\begin{tabular}{ccccccccccc}
\hline \multirow{2}{*}{ Age (days) } & \multicolumn{10}{c}{ Density $\left(\mathrm{kg} / \mathrm{m}^{3}\right)$} \\
\cline { 2 - 11 } & U0 & UC4 & UC8 & UC12 & US4 & US8 & US12 & UH4 & UH8 & UH12 \\
\hline 3 & 1907 & 1951 & 1897 & 1935 & 1884 & 1877 & 1878 & 1821 & 1759 & 1801 \\
7 & 1901 & 1922 & 1857 & 1859 & 1867 & 1920 & 1890 & 1731 & 1691 & 1760 \\
14 & 1772 & 1779 & 1792 & 1874 & 1713 & 1707 & 1707 & 1728 & 1638 & 1662 \\
28 & 1737 & 1784 & 1754 & 1820 & 1699 & 1688 & 1733 & 1662 & 1687 & 1786 \\
\hline
\end{tabular}

Table 3. Density of the Sieved Brick Samples

\begin{tabular}{ccccccccccc}
\hline \multirow{2}{*}{ Age (days) } & \multicolumn{10}{c}{ Density $\left(\mathrm{kg} / \mathrm{m}^{3}\right)$} \\
\cline { 2 - 11 } & S0 & SC4 & SC8 & SC12 & SS4 & SS8 & SS12 & SH4 & SH8 & SH12 \\
\hline 3 & 1782 & 1753 & 1836 & 1753 & 1658 & 1631 & 1801 & 1767 & 1659 & 1639 \\
7 & 1599 & 1755 & 1891 & 1788 & 1543 & 1699 & 1709 & 1589 & 1571 & 1579 \\
14 & 1562 & 1608 & 1795 & 1748 & 1607 & 1649 & 1745 & 1682 & 1676 & 1631 \\
28 & 1475 & 1652 & 1677 & 1669 & 1616 & 1544 & 1608 & 1574 & 1529 & 1557 \\
\hline
\end{tabular}

This implies that each of the additive tested had influence on the compressive strength development of compressed laterite bricks to a certain extent, which is indicative of certain forms of interaction taking place over time. For the cement stabilized samples (the control (C)), the strength gained improved as the cement content in the bricks increased and the curing age increased. The effect of cement stabilisation on strength gained when compared with that of the unstabilised samples was lowest at $4 \%$, ranging between $1.5 \%$ and $10 \%$ across the curing ages and particles size, while for $8 \%$ and $12 \%$ cement content, it ranges between $10 \%$ to $45 \%$ and $46 \%$ to $79 \%$, respectively, across the curing ages investigated. The gain in strength is being attributed to the hydration of cement paste which is known to contribute to the strength development of masonry units.

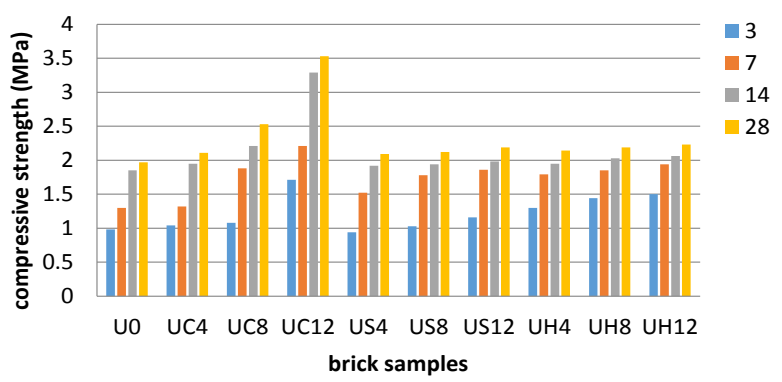

Figure 3: Variation of Compressive Strength for Brick Samples (unsieved)

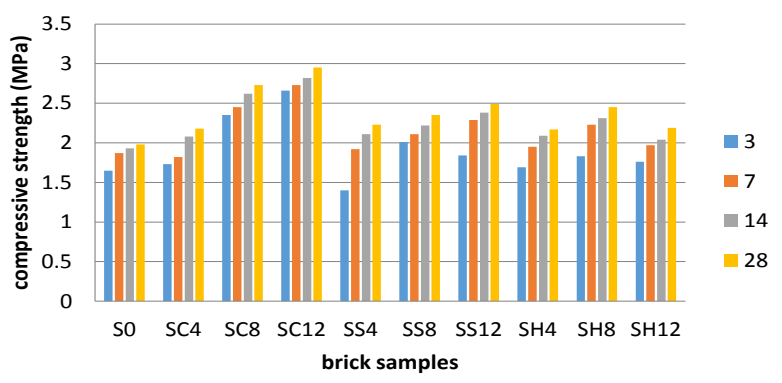

Figure 4: Variation of Compressive Strength for Bricks Samples (sieved)
However, the figures also showed that lignin stabilised samples had lower strength values compared to the cement stabilised samples. The softwood additives (S) had the lowest effect on strength gained ranging between $-15 \%$ to $17 \%, 5 \%$ to $37 \%$, and $7 \%$ to $43 \%$ for $4 \%, 8 \%$, and $12 \%$ stabilisation levels across the curing ages and particles sizes, while that of the hardwood additive $(\mathrm{H})$ ranges between $5 \%$ to $33 \%$, $10 \%$ to $47 \%$, and $5 \%$ to $53 \%$ respectively for $4 \%$, $8 \%$, and $12 \%$ additive content. A further comparison of these strength values with that of the unstabilised brick samples (i.e. 0\%), showed that the use of the additives resulted in strength increase except for the softwood additive at $4 \%$ stabilisation which has a lower value to that of the control. The gain in strength may be attributed to the effects of dispersion of the clay fraction [7], which enhances the stability of clayey laterite. The dispersion of clay particles has been attributed to the disposition of the clay mineral to isomorphous substitution which influences cation ion exchange and the charge potentials at the clay broken edges in relation to hydroxyl ion dissociation [14]. The amount of gain in strength depends on the extent of influence the additives had on the clay particles because it has a significant binding force which influences the response of the particles to the treatments.

Further comparison with previous related works $[16,17]$, revealed that the reduction in strength may be linked to the likely differences in the properties of the additives used and the method of extraction adopted for this study; as the additives used in most of the previous studies were industrial co-products.

The requirements of the Nigerian Building Code and Nigerian Building and Road Research Institute [18] stipulated a minimum dry compressive strength of 1.60 $\mathrm{MPa}$ and 2.0 $\mathrm{MPa}$ for bricks stabilised with 5\% cement at 7 and 28 days, respectively. On this basis, both the cement and wood additives stabilised bricks at all stabilisation levels and particles sizes met this 
minimum strength requirement with the exception of the cement and softwood lignin stabilized unsieved samples at $4 \%$ stabilisation, which had lower strength values and did not satisfy the minimum 7 days strength.

\section{Conclusion}

The paper examined the potential of two sawdust lignin extract as a stabilising additive for bricks in comparison with ordinary Portland cement stabilised bricks. The conclusions drawn from the study are as follow; the lignin additives from both the softwood and hardwood sawdust contributed to compressive strength gain in stabilised bricks; the strength gain improved with additive content, particle size, and curing age. The strength of cement stabilised bricks is influenced by the hydration of cement paste and formation of a new product during the process, while the wood additives enhanced strength by dispersion of and adhesion to fine particle surface. The softwood additive stabilised samples satisfied the minimum 7 days compressive strength of $1.60 \mathrm{MPa}$ recommended by the Nigerian Building and Road Research Institute, except at 4\% stabilisation level, while the 28 days strength of 2 $\mathrm{MPa}$ recommended by the National Building code was satisfied at all the levels. The hardwood additive stabilised samples satisfied both the 7 days and 28 days strength at all levels, but showed a reduction in strength at $12 \%$ content in the sieved samples.

\section{References}

1. Egenti C, Khatib, J., and Oloke, D., Conceptualisation and Pilot Study of Shelled Compressed Earth Block for Sustainable Housing in Nigeria, International Journal of Sustainable Built Environment, 3, 2014, pp. 72-86.

2. Addo, J.Q., Sanders, T.G., and Chenard, M., Road Dust Suppression: Effect on Maintenance Stability, Safety and the Environment, Phases 1-3, Report No. 04-156, Fargo, ND: MountainPlains Consortium (MPC), 2004.

3. Landon, B. and Williamson, R.K., Dust-abatement Materials: Evaluation and Selection, Transportation Research Record, 898, 1983, pp. 250-257.

4. Woods, K.B., Highway Engineering Handbook, $1^{\text {st }}$ ed. Minnesota: McGraw-Hill, 1960.

5. Nicholls, R.L. and Davidson, D.T., Polyacids and Lignin used with Large Organic Cations for Soil Stabilisation, Highway Research Board Proceedings, 37, 1958, pp. 517-537.

6. Palmer, J.T., Edgar, T.V., and Boresi, A.P., Strength and Density Modification of Unpaved Road Soils due to Chemical Additives, Report No. 95-39, Fargo, ND: Mountain-Plains Consortium (MPC), 1995.
7. Ceylan, H., Gopalakrishna, K., and Kim, S.,Soil Stabilization with Bioenergy Coproduct,Transportation Research Record, 2186, 2010, pp. 130137.

8. Lekha, B.M., Sarang, G., and Shankar A.U.R., Effects of Electrolyte Lignin and FlyAsh in Stabilising Black Cotton Soil, Journal of Transport, Infrastructure and Geotechnics, 2, 2015, pp. 87101. DOI 10.1007/s40515-015-0020-0

9. Canakci, H., Aram, A., and F. Celik, F., Soil Stabilization of Clay with Lignin, Rice Husk Powder and Ash, Geomechanics and Engineering, 8(1), 2015, pp. 67-79.

10. Maskell, D., Walker, P., and Heath, A., The Compressive Strength of Lignosulphonate Stabilised Extruded Earth Masonry Units, Terra 2012: $11^{\text {th }}$ International Conference on the Study and Conservation of Earthen Architecture Heritage, Lima, April 22-27, 2012.

11. Shulga, G., Vitolina, S., Shakels, V., Belkova, L., Cazacu, G., Vasile, C., and Nita, L., Lignin Separated from the Hydrolysate of the Hydrothermal Treatment of Birch Wood and its Surface Properties, Cellulose Chemistry and Technology, 46(5-6), 2012, pp. 307-318.

12. Silverstein, R.A., Chen, Y., Sharma-Shivappa, R.R., Boyette, M.D., and Osborne, J. A., Comparison of Chemical Pretreatment Methods for Improving Saccharification of Cotton Stalks, Bioresource Technology, 98, 2007, pp. 3000-3011.

13. Kumar, P., Barrett, D.M., Delwiche, M.J., and Stroeve, P., Methods for Pretreatment of Lignocellulosic Biomass for Efficient Hydrolysis and Biofuel Production,Industrial and Engineering Chemistry Research, 48(8), 2009, pp. 3713-3729. DOI: $10.1021 /$ ie801542g

14. Craig, R.F., Soil Mechanics, Seventh edition, SPON press, 1997.

15. Rix, C.G., Stabilisation of a Highly Plastic Clay Soil for the Production of Compressed Earth Blocks, A Master Thesis submitted to the Faculty of Architecture, University of the Witwatersrand, Johannesburg, 1998.

16. Gopalakrishnan, K., Ceylan, H., and Kim, S., Renewable Biomass-derived Lignin in Transportation Infrastructure Strengthening Applications, International Journal of Sustainable Engineering, 6(4), 2013, pp. 316-325.

17. Kim, S., Gopalakrishnan, K., and Ceylan, H., Moisture Susceptibility of Subgrade Soils Stabilised by Lignin-based Renewable Energy Co-product, ASCE Journal of Transportation Engineering, 138(11), 2012, pp. 1283-1290.

18. Raheem, A.A, Bello O.A., and Makinde, O.A., A Comparative Study of Cement and Lime Stabilized Lateritic Interlocking Blocks, Pacific Journal of Science and Technology, 11(2), 2010, pp. 27-34. 